\title{
Embrittlement of T-200 maraging steel in a hydrogen sulfide solution
}

\author{
L.W. Tsay ${ }^{a, *}$, Y.F. Hu ${ }^{\text {a }}$, C. Chen ${ }^{b, 1}$ \\ a Institute of Materials Engineering, National Taiwan Ocean University, 2 Pei-Ning Road, \\ Keelung 202, Taiwan, ROC \\ ${ }^{\mathrm{b}}$ Department of Materials Science and Engineering, National Taiwan University, Taipei 106, Taiwan, ROC
}

Received 2 July 2003; accepted 11 June 2004

Available online 18 September 2004

\begin{abstract}
Slow displacement rate tensile tests were carried out to investigate the effect of hydrogen embrittlement (HE) on notched tensile strength (NTS) and fracture characteristics of aged T-200 maraging steel. Hydrogen diffusivity, permeation flux and apparent hydrogen solubility were determined by an electrochemical permeation method, and correlated with the HE susceptibility and microstructures of the specimens. The results indicated that all aged specimens were susceptible to $\mathrm{HE}$ in the saturated $\mathrm{H}_{2} \mathrm{~S}$ solution, to different degrees. The susceptibility in the decreasing order of severity was observed to be under-aged, peakaged, and over-aged conditions. The main trend was that the specimen with the highest diffusivity and permeation flux of hydrogen had the greatest NTS loss. Reverted austenite, if present in the microstructure, acted as irreversible traps for hydrogen and hence, improved the HE resistance. At similar strength and hydrogen solubility level, the more reverted austenite the less susceptibility to HE of specimens was resulted. The detailed microstructures of distinct specimens and their performances in hydrogen-containing environments are discussed.
\end{abstract}

(C) 2004 Elsevier Ltd. All rights reserved.

\footnotetext{
* Corresponding author. Tel.: +886234 633192; fax: +886224625324.

E-mail addresses: b0186@mail.ntou.edu.tw (L.W. Tsay), gchen@ccms.ntu.edu.tw (C. Chen).

${ }^{1}$ Fax: +886223634562.
} 
Keywords: T-200 maraging steel; Sulfide stress cracking; Notch tensile strength; Hydrogen embrittlement; Hydrogen permeation

\section{Introduction}

It is known that sulfide stress cracking is a typical form of hydrogen embrittlement (HE) and can induce severe embrittlement in structural steels [1-4]. The presence of hydrogen in steels reduces the grain boundary cohesive strength [5] and fracture stress [6,7]. Meanwhile, a reduction in fracture toughness [8] and increased fatigue crack growth rate of steels [9-12] are reported due to HE. It is generally accepted that the resistance to $\mathrm{HE}$ of steels can be related to the fracture separation process, which in turn is dependent on the microstructure, cracktip stress intensity and hydrogen concentration around the crack tip [13]. The diffusion of hydrogen atoms is not only along the concentration gradient but also towards the location with high hydrostatic stresses [14-16]. Moreover, hydrogen has the tendency to accumulate and embrittle the elastic-plastic boundary of high strength steels [16], and it becomes more aggressive at increased stress concentration as in the presence of a notch [6]. Notched tensile strength (NTS) in hydrogen is reported to decrease significantly with increasing notch severity [17].

Maraging steels with the desirable qualities of high strength, high toughness and good formability have been widely utilized in military and aerospace applications. Maraging steels can be generally divided into three grades according to their yield strength levels, e.g. 200, 250, and $300 \mathrm{ksi}$. The $200 \mathrm{ksi}$ maraging steel is used primarily for demanding the utmost toughness/ductility circumstance [18]. In case of $18 \mathrm{Ni}$ cobalt-free maraging steels, titanium is used as one of the primary strengthening element to replace cobalt. The high strength of Ti-strengthened maraging steels is due to the precipitation of a fine dispersion of intermetallic particles in martensite. After solution heat treatment, the heavily dislocated martensite can be hardened by a single step aging treatment. Refined $\mathrm{Ni}_{3} \mathrm{Ti}$, or more exactly $(\mathrm{NiFe})_{3}(\mathrm{TiMo})$, intermetallic precipitates are coherent with the matrix in the under-aged condition and lose their coherency as the aging temperature increases [19]. Reverted austenite in the lamellar form appears in the over-aged condition and becomes more extensive with increasing aging temperature [19-21]. In addition, the presence of reverted austenite might alter the strength and toughness of the alloy considerably $[20,22,23]$. In previous studies, the HE susceptibility of two ultra-high strength steels in the saturated $\mathrm{H}_{2} \mathrm{~S}$ solution was correlated to permeation properties and microstructures of the steels [24,25].

The purpose of this investigation was to study HE susceptibility of T-200 maraging steel aged at different temperatures using slow displacement rate tensile tests. The loss of NTS in the saturated $\mathrm{H}_{2} \mathrm{~S}$ solution as compared to the NTS in air was used to index the HE susceptibility of specimens. Electrochemical permeation was performed to study hydrogen permeation behavior and the results were correlated to the microstructures and NTS losses of specimens. 


\section{Material and experimental procedures}

The T-200 maraging steel used in this investigation was purchased from Teledyne Vasco in the plate form with a nominal thickness of $3.4 \mathrm{~mm}$. The chemical composition of the alloy in weight percent was $18.84 \mathrm{Ni}, 2.85 \mathrm{Mo}, 0.8 \mathrm{Ti}, 0.021 \mathrm{C}, 0.075 \mathrm{Si}$, $0.023 \mathrm{Mn}, 0.005 \mathrm{P}, 0.003 \mathrm{~S}$, and balance Fe. The alloy was solution-treated in an inert environment at $816^{\circ} \mathrm{C}\left(1500^{\circ} \mathrm{F}\right)$ for $1 \mathrm{~h}$ and then air-cooled to room temperature. Aging treatments were then performed at $427^{\circ} \mathrm{C}\left(800^{\circ} \mathrm{F}\right), 482^{\circ} \mathrm{C}\left(900^{\circ} \mathrm{F}\right)$ and $538^{\circ} \mathrm{C}\left(1000^{\circ} \mathrm{F}\right)$ for $4 \mathrm{~h}$; based on aging temperature, the specimens were designated as H800 (under-aged), H900 (peak-aged), and H1000 (over-aged) specimens, respectively. The hardness of the specimens changed marginally with aging treatment. Hardness of $\mathrm{H} 900$ specimen $\left(H_{\mathrm{RC}} 45.3\right)$ was slightly higher as compared with the H800 specimen $\left(H_{\mathrm{RC}} 43.7\right)$ or the $\mathrm{H} 1000$ specimen $\left(H_{\mathrm{RC}} 42.6\right)$. It was obvious that $\mathrm{T}-200$ specimens aged at the temperature range of $800-1000^{\circ} \mathrm{F}$ would have a similar strength, even through they consisted of distinct microstructures.

The dimensions of notched tensile specimens utilized in this study are shown in Fig. 1. Double-edge notch specimen, having a notch radius of about $100 \mu \mathrm{m}$, was made by an electrode-discharge wire cutter. Notched tensile specimens were tested in a saturated $\mathrm{H}_{2} \mathrm{~S}$ solution at constant displacement rates (crosshead speeds) of 0.0075 or $0.0015 \mathrm{~mm} / \mathrm{min}$. The saturated $\mathrm{H}_{2} \mathrm{~S}$ solution was prepared according to the NACE standard (TM-01-77-86). The results presented were an average of at least three specimens for each testing condition. The susceptibility to HE was expressed as the percentage loss in NTS between $\mathrm{H}_{2} \mathrm{~S}$ and air environment as given below:

$$
\text { NTS loss }(\%)=\frac{\text { NTS (in air) }- \text { NTS }\left(\text { in } \mathrm{H}_{2} \mathrm{~S}\right)}{\text { NTS (in air) }}
$$

Electrochemical permeation technique originally developed by Devanathan and Stachurski [26] was employed to determine the hydrogen permeation of specimens. The specimen after grinding and polishing, was electroplated with $\mathrm{Pd}$ of $0.2 \mu \mathrm{m}$ thick on hydrogen exit side. The exposed surface area $\left(1 \mathrm{~cm}^{2}\right)$ of the specimen $(0.25 \mathrm{~mm}$ thick) acted as working electrode. The cathodic (hydrogen entry) side was galvano-statically polarized and charged with a constant current density of $20 \mathrm{~mA} / \mathrm{cm}^{2}$ in an electrolyte consisting of $0.1 \mathrm{~N} \mathrm{NaOH}$ added with $20 \mathrm{mg} \mathrm{As}_{2} \mathrm{O}_{3} / 1$ to enhance hydrogen adsorption. The anodic (hydrogen exit) side was held at a constant

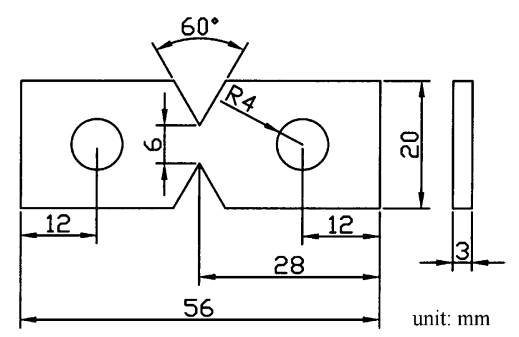

Fig. 1. Configuration of the notched tensile specimen used in the experiment. 
potential of $+200 \mathrm{mV}$ with reference to saturated calomel electrode (SCE) in $0.1 \mathrm{~N}$ $\mathrm{NaOH}$ at room temperature. Solutions on both sides of the cell were deoxygenated by continuous purging of $\mathrm{N}_{2}$ bubbles. The potentiostatic current gave a direct measurement of the hydrogen flow rate, and hydrogen permeation transients were recorded on a strip chart recorder. The effective hydrogen diffusivity $\left(D_{\text {eff }}\right)$, permeation flux $\left(J_{\infty} L\right.$, where $J_{\infty}$ is the steady state flux of hydrogen and $L$ is the specimen thickness), and the apparent hydrogen solubility $\left(C_{\text {app }}\right)$ were determined according to the equations described in a previous study [24]. Replicate permeation experiments were performed and the presented results were the average of three tests for each type of specimens under identical conditions.

Tensile-fractured specimens were examined by a Hitachi S4100 scanning electron microscope (SEM), with emphasis on the crack initiation sites and regions showing changes in fracture appearance. In addition, thin foil specimens were prepared by a standard jet-polisher for the examination under a JEOL-2000EX transmission electron microscope (TEM).

\section{Results}

\subsection{Microstructural observations}

TEM micrographs of H800, H900, and H1000 specimens are shown in Fig. 2. The microstructures of the under-aged (H800) specimens consisted of ultra-fine precipitates (barely visible in the photograph) in the martensite matrix with a high dislocation density (Fig. 2(a)), in which the absence of reverted austenite is also noticed. In the case of the peak-aged (H900) specimens, a homogeneous distribution of fine precipitates in the matrix and the existence of reverted austenite (indicated by arrows) mainly at martensite interlath boundaries can be seen in Fig. 2(b). It appeared that the precipitates become coarsened with increasing aging temperature and/or time. Fig. 2(c) exhibits the presence of more reverted austenite (indicated by arrows) together with coarse $\mathrm{Ni}_{3} \mathrm{Ti}$ incoherent precipitates in the martensite matrix of the over-aged (H1000) specimens. It was noticed that distinct microstructures associated with specimens aged at different temperatures could affect the HE and hydrogen permeation behavior of the material significantly.

\subsection{Notched tensile test}

The NTS values of aged T-200 specimens tested in air and saturated $\mathrm{H}_{2} \mathrm{~S}$ solution at two displacement rates are shown in Fig. 3. In air, the H900 specimen had a slightly higher NTS than that of H800 and H1000 specimens, but the difference among them was insignificant. However, in case of specimens tested in the saturated $\mathrm{H}_{2} \mathrm{~S}$ solution at a displacement rate of $0.0075 \mathrm{~mm} / \mathrm{min}$, the effect of HE on NTS became quite obvious as reflected by the reduction in NTS. The index of HE susceptibility in the decreasing order of severity was H800, H900, and H1000 specimens, which corresponded to NTS losses of $49 \%, 32 \%$, and $19 \%$, respectively. Similar trend 

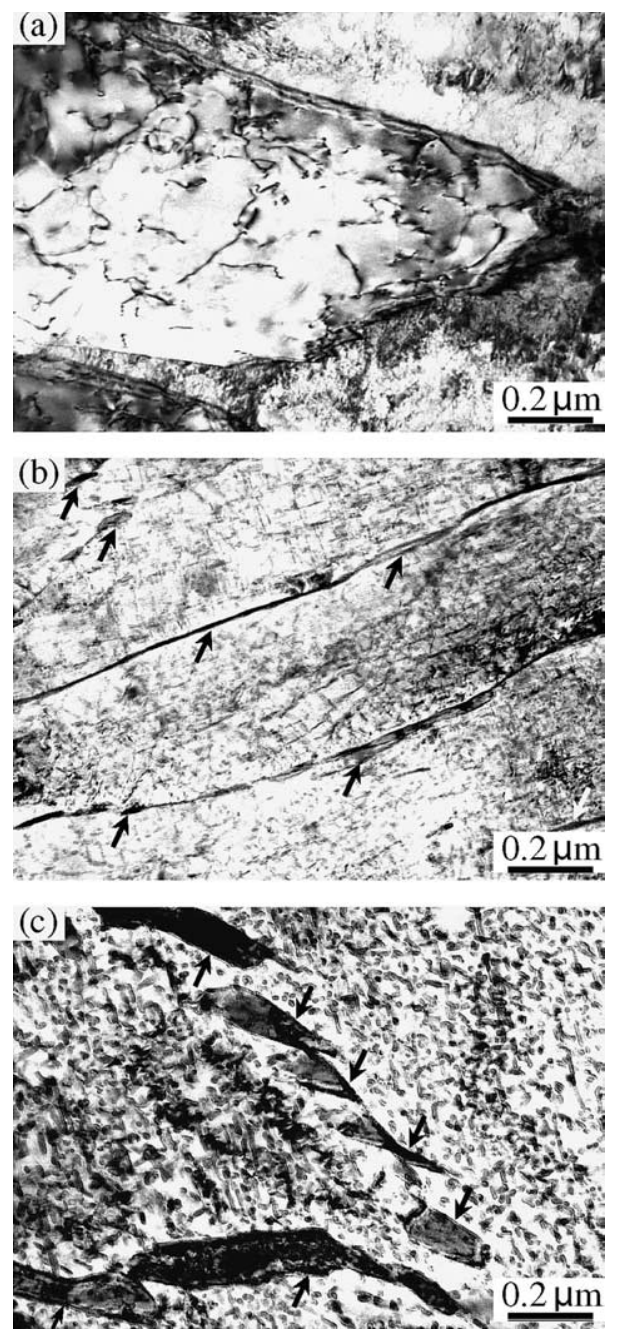

Fig. 2. TEM micrographs of (a) H800, (b) H900, and (c) H1000 specimens. Reverted austenite is indicated by arrows.

in HE susceptibility index was observed for specimens tested at $0.0015 \mathrm{~mm} / \mathrm{min}$ displacement rates with the exception a higher NTS loss for a given specimen. In gaseous hydrogen, T-200 specimens in the peak-aged and over-aged conditions are resistant to HE, while under-aged specimens are susceptible to HE [27]. In this study, peak-aged and over-aged specimens were susceptible to $\mathrm{HE}$ in the saturated $\mathrm{H}_{2} \mathrm{~S}$ solution but at different degrees. The results indicated that the saturated $\mathrm{H}_{2} \mathrm{~S}$ solution was more aggressive than gaseous hydrogen to embrittle the T-200 maraging steel. 


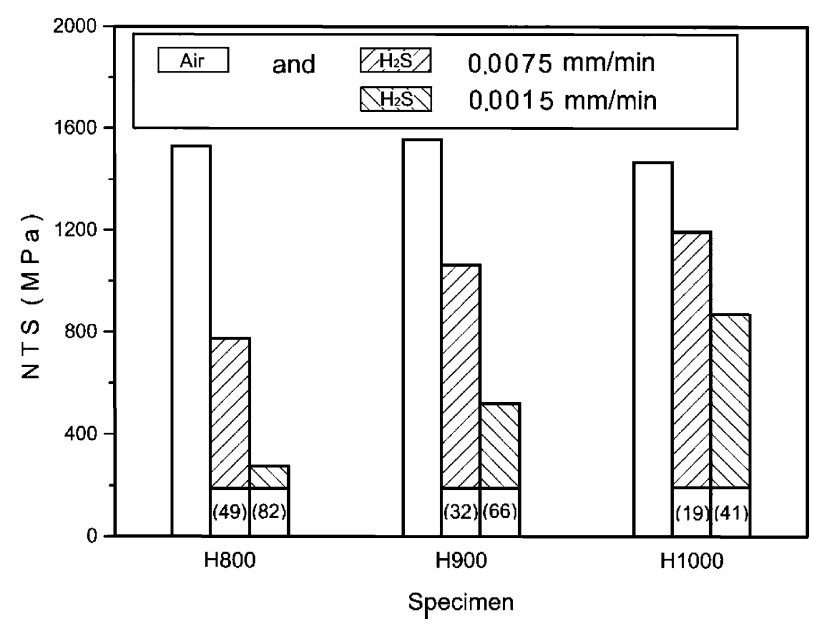

Fig. 3. Notched tensile strength (NTS) of aged specimens tested in air and saturated $\mathrm{H}_{2} \mathrm{~S}$ solution. Note that the percentage within parentheses indicates the NTS loss in saturated $\mathrm{H}_{2} \mathrm{~S}$ solution.

Fig. 4 shows the tensile load vs. displacement curves for notched specimens tested in the saturated $\mathrm{H}_{2} \mathrm{~S}$ solution at two displacement rates. They also revealed that the decrease in displacement rates i.e. prolonged interaction time between the specimen and hydrogen, would result in a marked decrease in NTS for all specimens. On the other hand, the total displacement, which represented the localized deformation prior to fracture, could also be used as an indication of the relative HE susceptibility of specimens. At lower displacement rate, higher susceptibility to $\mathrm{HE}$ and lower total displacement of specimens would be expected. The total displacement for notch specimens at the displacement rate of $0.0075 \mathrm{~mm} / \mathrm{min}$ was observed to be $1.12,1.45$, and $1.65 \mathrm{~mm}$ for $\mathrm{H} 800, \mathrm{H} 900$, and $\mathrm{H} 1000$ specimens, respectively. Reducing the displacement rate to $0.0015 \mathrm{~mm} / \mathrm{min}$, the total displacement for each specimen was lowered further $(0.61,0.84$, and $1.03 \mathrm{~mm}$ for $\mathrm{H} 800, \mathrm{H} 900$, and $\mathrm{H} 1000$ specimens, respectively), thus illustrating the increased HE susceptibility at a lower displacement rate.

\subsection{Hydrogen permeation}

Table 1 lists the permeation results including effective hydrogen diffusivity ( $\left.D_{\text {eff }}\right)$, permeation flux $\left(J_{\infty} L\right)$, and apparent hydrogen solubility $\left(C_{\text {app }}\right)$ of various specimens. The data indicated that the effective diffusivity and permeation flux of hydrogen decreased with increasing the aging temperature of specimens. The high diffusivity and permeation flux of hydrogen could also be related to the high susceptibility to $\mathrm{HE}$ as revealed by the great NTS loss in $\mathrm{H}_{2} \mathrm{~S}$ for $\mathrm{H} 800$ specimen. Apparent hydrogen solubility was similar for $\mathrm{H} 800, \mathrm{H} 900$, and $\mathrm{H} 1000$ specimens, implying that the amount of hydrogen trapped in these specimens was more or less similar for all three aging treatments. In fact, the $C_{\text {app }}$ is dependent on the amount and nature of trapping sites - both irreversible and reversible traps in the specimen. For 

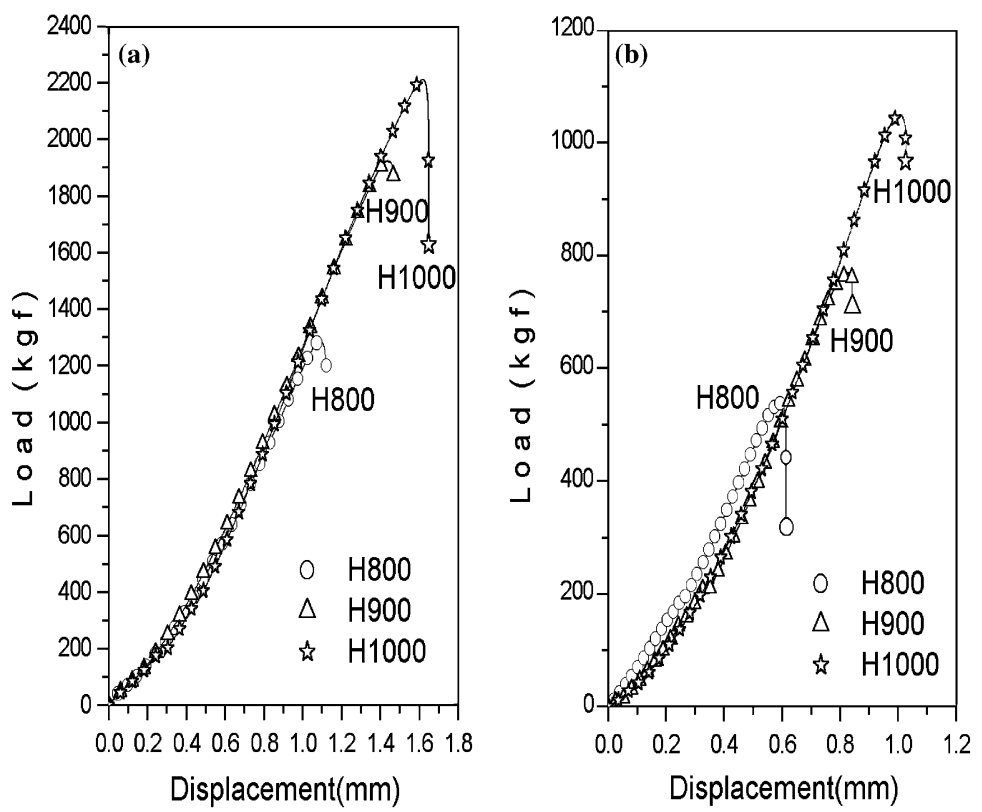

Fig. 4. Tensile load vs. displacement curves for specimens tested in the saturated $\mathrm{H}_{2} \mathrm{~S}$ solution at the displacement rate of (a) 0.0075 and (b) $0.0015 \mathrm{~mm} / \mathrm{min}$.

Table 1

Permeation results of T-200 maraging steel specimens aged at various temperatures

\begin{tabular}{llll}
\hline & $\mathrm{H} 800$ & $\mathrm{H} 900$ & $\mathrm{H} 1000$ \\
\hline$D_{\text {eff }}\left(\mathrm{m}^{2} / \mathrm{s}\right)$ & $2.92 \times 10^{-12}$ & $2.55 \times 10^{-12}$ & $1.97 \times 10^{-12}$ \\
$J_{\infty} L(\mathrm{~mol} \mathrm{H} / \mathrm{sm})$ & $3.48 \times 10^{-10}$ & $2.70 \times 10^{-10}$ & $2.23 \times 10^{-10}$ \\
$C_{\text {app }}\left(\mathrm{mol} \mathrm{H} / \mathrm{m}^{3}\right)$ & 119 & 106 & 113 \\
\hline
\end{tabular}

example, reverted austenite (irreversible trap) is considered to be a strong (good) trap, which would decrease HE susceptibility of the material. Consequently, more the reverted austenite, the less the specimen would be susceptible to HE- a case that would be expected to be in H1000 specimens.

\subsection{Fracture morphology}

Fig. 5(a) is a typical fractograph of aged T-200 maraging steel specimen after notched tensile test in air, in which two symmetrical triangular-shaped areas of flat fracture surrounded by slant fracture can be seen. H800, H900, and H1000 specimens exhibited nearly the same flat fracture and had a dimple fracture within the flat fracture region. In contrast, only flat fracture was found for the same specimens tested in the saturated $\mathrm{H}_{2} \mathrm{~S}$ solution as displayed in Fig. 5(b). Flat fracture represented the region under higher constraint and as a result, the specimen fractured 

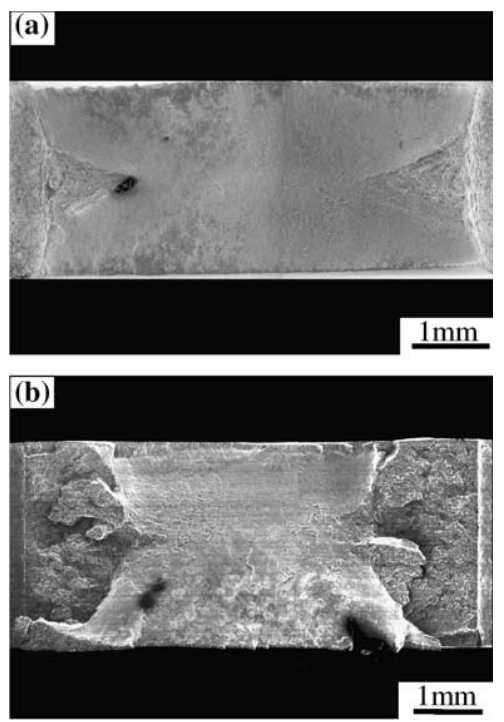

Fig. 5. Typical macrographs of the aged specimens after notched tensile tests in (a) air and (b) a saturated $\mathrm{H}_{2} \mathrm{~S}$ solution at a displacement rate of $0.0075 \mathrm{~mm} / \mathrm{min}$.

in plain strain condition during tensile loading. Also, the region of flat fracture was affected most by hydrogen and often associated with a change in fracture modes if any. The extent of brittle fracture could also be linked to the HE susceptibility of the material, which increased with decreasing the aging temperature of specimens.

SEM fractographs of specimens tested in the saturated $\mathrm{H}_{2} \mathrm{~S}$ solution under various conditions are present in Fig. 6. Intergranular (IG) fracture was observed at the corners of all the specimens regardless of the displacement rate. However, the intergranular fracture was more predominant for the specimens tested at a lower displacement rate (Fig. 6(a)). Moreover, the extent of intergranular fracture varied among the aged specimens, being the largest for the H800 specimen and the smallest for the H1000 specimen. In the region ahead of the notch root, quasi-cleavage (QC) fracture was found for $\mathrm{H} 900$ and $\mathrm{H} 1000$ specimens at a displacement rate of $0.0075 \mathrm{~mm} /$ min (Fig. 6(b)), but not for the H800 specimen, which indicated intergranular fracture (IG). Lowering the displacement rate to $0.0015 \mathrm{~mm} / \mathrm{min}$, the region of IG fracture (Fig. 6(c)) increased in all specimens. Furthermore, the change in fracture modes from IG to QC prior to the final (dimple) rupture (Fig. 6(d)) for all specimens was noted.

\section{Discussion}

It has been reported that hydrogen permeation properties can be related to the material microstructures [28-30]. Xu et al. [29] reported that dislocations are the 

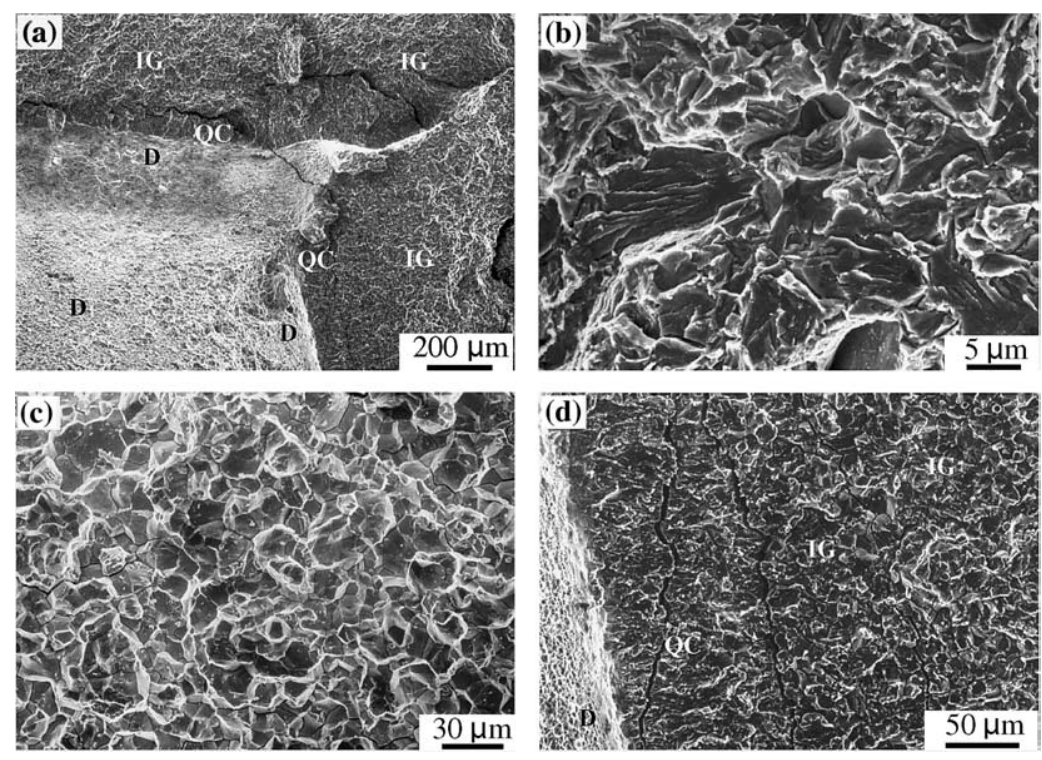

Fig. 6. SEM fractographs of notched tensile specimens tested in saturated $\mathrm{H}_{2} \mathrm{~S}$ solution: (a) macrograph showing one corner of the $\mathrm{H} 900$ specimen under $0.0015 \mathrm{~mm} / \mathrm{min}$ displacement rate, (b) QC fracture at the notch front of $\mathrm{H} 900$ and $\mathrm{H} 1000$ specimens tested at a displacement rate of $0.0075 \mathrm{~mm} / \mathrm{min}$, (c) predominantly IG fracture for all specimens tested at $0.0015 \mathrm{~mm} / \mathrm{min}$ and (d) the change in fracture modes from IG to QC prior to the final rupture (dimple fracture, indicated by $D$ ).

dominant trapping sites for hydrogen in a low carbon martensite. $18 \mathrm{Ni}$ maraging steel in the peaked-aged condition contains three types of trapping sites [31]: (1) intermetallic precipitates, $\mathrm{Ni}_{3} \mathrm{Ti}$ and $\mathrm{Ni}_{3} \mathrm{Mo}$, appear to be reversible traps; (2) martensite boundaries are possibly quasi-irreversible traps; (3) $\mathrm{TiC} / \mathrm{Ti}(\mathrm{CN}$ ) particles are thought to be irreversible traps. Dislocations usually are regarded as the reversible trapping sites. In the present work, the dislocations in the material decreased, but the amount of incoherent particles and reverted austenite increased with increasing the aging temperature. As a result, the number of irreversible trapping sites appeared to increase at the expense of reversible trapping sites with the increase in aging temperature. As the strength levels for the different aged specimens were alike, one could expect similar plastic zone size and critical hydrogen concentration ahead of the notch tip for these specimens. Therefore, the HE susceptibility of the aged specimens could be related to the inherent microstructures and hydrogen permeation behavior of their respective conditions.

Even at the same strength level, the value of $C_{\text {app }}$ itself might not correlate well to NTS losses of various specimens in the saturated $\mathrm{H}_{2} \mathrm{~S}$ solution unless the nature of hydrogen traps, e.g. irreversible and reversible traps, could be identified. Apparently, the amount of irreversible hydrogen traps (reverted austenite) was the highest in H1000, whereas H800 specimens consisted of the greatest reversible traps (dislocations) among the specimens. For simplicity, the $C_{\text {app }}$ of all the specimens 
$\left(106-119 \mathrm{~mol} \mathrm{H} / \mathrm{m}^{3}\right)$ could be considered roughly the same. The foregoing discussion could best be illustrated by comparing H800 and H1000 specimens that had essentially similar tensile strength but with different microstructures and NTS losses. Pressoure and Bernstein [32] reported that irreversible traps would help in delaying the onset of hydrogen-induced cracking. Pound [31] on the contrary, reported that HE susceptibility of materials is found to increase with increasing the irreversible trapping constant which was related to the density of irreversible traps in the material. The results of the present study confirmed that a strong hydrogen trap such as reverted austenite is beneficial to resist $\mathrm{HE}$ and were in agreement with Pressoure and Bernstein's work [32,33].

As shown in Fig. 3, the H800 specimen had the highest susceptibility to HE among aged specimens being tested. The higher diffusivity and permeation flux of under-aged specimens (Table 1) implied rapid and sufficient supply of hydrogen atoms to the strained area ahead of notch tip. In addition to this, the large amount of hydrogen trapped in reversible sites might also migrate to the strained region during slow displacement rate tests, leading to a great NTS loss for under-aged specimens. On the other hand, strong trapping of reverted austenite in the H1000 specimen could impede the hydrogen diffusion to the strained region. Consequently, the hydrogen concentration within the plastic zone around the notch tip reduced and led to a lower HE susceptibility. This was consistent with the observation on the over-aged specimen that had the lowest $D_{\text {eff }}$ and the highest amount of irreversible traps among the specimens being evaluated. Additionally, the existence of ductile austenite in the matrix might blunt the crack tip, causing an enlarged plastic zone and a reduced HE susceptibility of specimens. In the H900 specimen, the amount of reverted austenite was less compared to H1000 specimen. Hence, the peak-aged specimen was more susceptible to HE than the over-aged specimen. It was concluded that reverted austenite having the tendency to absorb hydrogen at interfaces or within itself could enhance the HE resistance of the material.

Fractographic examinations of the embrittled specimens revealed the presence of intergranular fracture at the corners of the specimens. It was reasonable to assume that more hydrogen atoms were supplied to corners than to the notch front (twodimensional vs. one-dimensional supply of hydrogen), resulting in a more severe embrittlement (intergranular fracture) of the specimen. It was expected the increase in crack growth rates occurred as the crack grew into the interior of specimens, in particular, at the final stage of fracture. Fractographs also suggested the change in fracture modes from the exterior to the interior, e.g. intergranular fracture, quasicleavage, and final dimple rupture (Fig. 6(d)). The extent of intergranular fracture became larger as the displacement rate decreased. It is known that diffusion of hydrogen is faster along grain boundaries than the matrix at room temperature. At a reduced displacement rate, the accumulation and diffusion of hydrogen into the microstructure was significant along grain boundaries, resulting in intergranular separations under straining. In contrast, the short-time interaction of hydrogen with materials caused a reduced damage at grain boundaries under high deformation rate. Consequently, quasi-cleavage fracture was observed in the embrittled area, particularly in the region experiencing a faster subcritical crack growth. More work on the 
correlation between hydrogen diffusion and deformation rate is required to verify the change in fracture mode of maraging steels in hydrogen-containing environments.

\section{Conclusions}

1. T-200 maraging steel was quite susceptible to sulfide stress cracking. The rank of HE susceptibility in the decreasing order was H800 (under-aged), H900 (peakaged), and H1000 (over-aged) specimens. These specimens had nearly the same strength but with distinct microstructures and hydrogen permeation behavior. The more reverted austenite (irreversible hydrogen trap) in the specimen, the less HE susceptibility. Decreasing the displacement rate of the test would result in a marked NTS loss for all specimens.

2. The hydrogen diffusivity and permeation flux decreased with increasing aging temperature. The specimen with the highest diffusivity and permeation flux of hydrogen had the greatest NTS loss. The high diffusivity and permeation flux represented the rapid and sufficient supply of hydrogen atoms to the strained area ahead of notch tip, leading to an obvious loss of NTS for the under-aged specimen. On the other hand, strong trapping of reverted austenite in the over-aged specimen impeded hydrogen diffusion to the strained region, and resulting in a low NTS loss.

3. The extent of intergranular fracture increased with decreasing the displacement rate due to enhanced hydrogen/material interaction. This implied that hydrogen tended to diffuse and trap along grain boundaries, resulting in an intergranular separation of specimens under straining. In contrast, a short interaction time associated with a high deformation rate reduced the influence of $\mathrm{HE}$ at grain boundaries. Consequently, quasi-cleavage was observed in the embrittled area, particularly in the region experiencing a fast subcritical crack growth.

\section{Acknowledgement}

The authors gratefully acknowledge the support from the National Science Council of the Republic of China (contract no. NSC 89-2216-E-019-001).

\section{References}

[1] B.J. Berkowitz, F.H. Heubaum, Corrosion 40 (5) (1984) 240-245.

[2] R. Gee, Z.Y. Chen, Corros. Sci. 37 (12) (1995) 2003-2011.

[3] L.W. Tsay, W.L. Lin, Corros. Sci. 40 (4/5) (1998) 577-591.

[4] W. Kindlein Jr., P.T. Schilling, R.M. Schroeder, I.L. Müller, Corros. Sci. 34 (8) (1993) 1243-1250.

[5] A. Vyrostkova, B. Stefan, Metall. Mater. 28 (6) (1990) 426-432.

[6] D. Hardie, S. Liu, Corros. Sci. 38 (5) (1996) 721-733.

[7] T.L. Chang, L.W. Tsay, C. Chen, Mater. Sci. Eng. A 316 (1/2) (2001) 153-160. 
[8] H.I. McHenry, P.T. Purtscher, T.R. Shive, Corros. Sci. 27 (10/11) (1986) 1041-1057.

[9] L. Tau, S.L.I. Chan, C.S. Shin, Corros. Sci. 38 (11) (1996) 2049-2060.

[10] C.A. Hippsley, C.E. Lane, Mater. Sci. Technol. 6 (8) (1990) 735-742.

[11] L.W. Tsay, W.B. Huang, C. Chen, Fat. Fract. Eng. Mater. Struct. 20 (7) (1997) 1033-1041.

[12] J.H. Chuang, L.W. Tsay, C. Chen, Int. J. Fat. 20 (7) (1998) 531-536.

[13] C.D. Beachem, Metall. Mater. Trans A 3 (1972) 437-451.

[14] J. Toribio, A.M. Lancha, M. Elices, Mater. Sci. Eng. A 145 (1991) 167-177.

[15] J. Toribio, J. Mater. Sci. 28 (1993) 2289-2298.

[16] A.T. Yokobori Jr., T. Nemoto, K. Satoh, T. Yamada, Eng. Fract. Mech. 55 (1996) 47-60.

[17] S. Liu, Z. Ziyong, K. Wei, J. Mater. Sci. Technol. 12 (1996) 51-56.

[18] S. Floreen, A.M. Bayer, Symposium of TMS Annual Meeting Phoenix, AZ, 1988, pp. 39-54.

[19] V.K. Vasudevan, S.J. Kim, C.M. Wayman, Met. Trans. 21A (10) (1990) 2655-2668.

[20] L.W. Tsay, W.B. Huang, Y.M. Li, C. Chen, J. Mater. Eng. Perform 6 (2) (1997) 177-181.

[21] L.W. Tsay, W.B. Huang, C. Chen, J. Mater. Eng. Perform 6 (2) (1997) 182-186.

[22] D.T. Peter, Trans. ASM 61 (1) (1968) 62-74.

[23] L.W. Tsay, C. Chen, S.L.I. Chan, Int. J. Mater. Product Tech. 10 (1/2) (1995) 132-142.

[24] L.W. Tsay, W.C. Lee, R.K. Shiue, J.K. Wu, Corros. Sci. 44 (9) (2002) 2101-2118.

[25] L.W. Tsay, W.C. Lee, W.C. Luu, J.K. Wu, Corros. Sci. 44 (2) (2002) 1311-1327.

[26] M.A. Devanathan, Z. Stachurski, Proc. Roy. Soc. (Lond.) A 270 (1962) 90-102.

[27] C.P. Wu, L.W. Tsay, C. Chen, Mater. Sci. Eng. A 346 (2003) 302-309.

[28] R. Valentini, A. Solina, Mater. Sci. Technol. 10 (10) (1994) 908-914.

[29] J. Xu, X.Z. Yuan, X.K. Sun, B.M. Wei, Scrip. Metall. 29 (1993) 925-930.

[30] N. Parvathavarthini, S. Saroja, R.K. Dayal, J. Nucl. Mater. 264 (1999) 35-47.

[31] B.G. Pound, Acta Metall. Mater. 38 (12) (1990) 2373-2381.

[32] G.M. Pressouyre, I.M. Bernstein, Acta Metall. 27 (1) (1979) 89-100.

[33] G.M. Pressouyre, I.M. Bernstein, Metall. Trans. 9A (11) (1978) 1571-1580. 